\title{
EM BUSCA DE UMA AGENDA BRASILEIRA DE PESQUISA EM ESTRATÉGIA DE MARKETING
}

\section{RESUMO}

Há duas questões históricas no Marketing ainda não resolvidas: o seu poder nas estratégias das grandes empresas e a relevância da disciplina. Essas questões ganharam destaque no contexto da globalização, especialmente em países tidos como menos desenvolvidos, devido à ampliação de assimetrias no mercado e na academia. $O$ artigo sugere que o poder reduzido do marketing na grande empresa era questão central em pesquisa no âmbito de estratégia de marketing nos anos 1980 e que o conceito de orientação para o mercado enfraqueceu o interesse por esse âmbito a partir dos anos 1990. O autor argumenta que a superação desse problema requer não somente a aversão à academia dominante, mas também a compreensão de interesses e mecanismos sócio-históricos que moldam a área nos Estados Unidos. Ao final, discute-se por que desenvolver uma agenda brasileira de pesquisa em estratégia de marketing e sugere-se um guia para a constituição dessa agenda.

\section{Alexandre Faria \\ FGV-EBAPE}

\begin{abstract}
There are two historical issues in marketing that have not been sorted out: the power of marketing in the strategies of big companies, and the relevance of the discipline. These issues became more important in the globalization era because of the enhancement of asymmetries within the market and the academy. The article shows that the low power of marketing within the big company was a central topic for research in the domain of marketing strategy and that the concept of market orientation weakened the interest on this domain as from the early 1990 s. The author argues that in order to overcome this problem it is necessary not just going against the dominant academy, but also understanding sociohistorical interests and mechanisms that shape the area in the U.S. In the end the article provides suggestions for the development of a Brazilian research agenda on marketing strategy.
\end{abstract}

PALAVRAS-CHAVE Estratégia de marketing, orientação para o mercado, história do marketing, sociologia do conhecimento, estudos críticos em gestão.

KEYWORDS Marketing strategy, market orientation, marketing history, sociology of knowledge, critical management studies. 


\section{INTRODUÇÃO}

Devido ao ocaso do modelo socialista de Estado, ao anúncio do fim da Guerra Fria e ao advento da globalização a partir do início dos anos 1990, temos observado nos últimos anos a expansão da economia de mercado e a crescente importância do marketing em diversos países. Diversos autores de marketing, principalmente nos Estados Unidos, denominam essa realidade da era da estratégia orientada para o mercado. Inspirados pela difusão do conceito de orientação para o mercado (OPM), e sem reconhecer debates sobre a relevância das disciplinas de Marketing (Brownlie et al., 1999; Hunt, 1994; Wilkie e Moore, 2003) e Estratégia (Shrivastava, 1986; Whittington, 2001), esses autores argumentam que o marketing ganhou responsabilidade estratégica nas grandes empresas por causa da expansão da economia de mercado em escala global (Cravens, 1998; Webster, 1992).

Tamanho entusiasmo pela ascensão do chamado marketing estratégico é preocupante, visto que a globalização ampliou e evidenciou diversos tipos de assimetria (Hirst e Thompson, 2002), especialmente em economias tidas como menos desenvolvidas (Gentry et al., 1995). Isso explica o crescente interesse de pesquisadores por insatisfação do consumidor (Bougie et al., 2003; Chauvel, 2000) e por abordagens críticas extremas em marketing (veja Burton, 2001). Esses interesses recentes ecoam questionamentos históricos sobre a relevância da área e do poder efetivo do marketing para e na grande empresa e na sociedade (Hunt e Lambe, 2000; Varadarajan e Jayachandran, 1999; Brownlie et al., 1999).

Nesse contexto marcado por contradições, o âmbito da estratégia de marketing reassume central importância para a área por traduzir dois importantes objetivos: (a) elevar a autonomia do marketing dentro da grande empresa, e (b) transferir o controle estratégico do marketing da alta hierarquia para os praticantes próximos ao mercado (Wind e Robertson, 1983; Greenley, 1989). Apesar de esses objetivos terem sido esquecidos pela literatura contemporânea, este artigo mostra que eles ganharam importância a partir do início dos anos 1990 devido a assimetrias evidenciadas e ampliadas pela globalização.

$\mathrm{O}$ autor deste artigo mostra por que o conceito de OPM é um dos principais obstáculos ao desenvolvimento do âmbito da estratégia de marketing e como os antecedentes históricos e as implicações correspondentes podem ser atenuados por meio da constituição de uma agenda brasileira de pesquisa que deve ser aplicada no Brasil e pode ser aplicada em outros contextos.

\section{EM DEFESA DA CONSTITUIÇÃO DE UMA AGENDA DE PESQUISA NO BRASIL}

Nesta seção mostra-se que o desenvolvimento de agendas de pesquisa em estratégia de marketing é particularmente importante em países tidos como menos desenvolvidos, tais como o Brasil, devido a dois tipos de assimetria que foram evidenciados e ampliados pela globalização, quais sejam: assimetria de mercado e assimetria acadêmica.

\section{Assimetria de mercado}

A constituição de agendas locais de pesquisa em estratégia de marketing é fundamental em países como o Brasil porque, em termos históricos, as relações de poder entre empresas e consumidores são bem mais assimétricas em economias menos desenvolvidas do que nas mais desenvolvidas (Souza, 2003; Churchill e Peter, 2000). A globalização ampliou e tornou evidente esse problema. Enquanto certos consumidores em economias mais desenvolvidas chegam a usar o ato de consumir como ato político em resposta ao crescente poder das corporações (Korten, 2001), os consumidores no Brasil, por exemplo, ainda não obtiveram o adequado reconhecimento de seus direitos legais, apesar dos grandes avanços obtidos a partir da efetivação do Código de Defesa do Consumidor, em 1990.

As estratégias de marketing das grandes corporações costumam ser abusivas em economias tidas como menos desenvolvidas por não seguirem os princípios de marketing (Sethi e Post, 1979). Esse quadro vem ficando cada mais preocupante devido ao avanço da globalização e da correspondente disseminação de práticas e discursos baseados nas idéias de "livre mercado" e de "livre empresa". Isso ajudou a elevar, de forma exagerada, o poder político e econômico das grandes corporações em relação aos consumidores e mesmo aos governos locais, em detrimento do poder relativo dos princípios de marketing dentro dessas empresas.

Esse cenário de assimetria faz com que a implementação de um dos mais importantes princípios estratégicos do marketing nesse contexto da globalização deixe de ser atendido. As empresas devem não meramente satisfazer os consumidores, mas devem não abusar deles, o que é particularmente mais fácil para as empresas de grande porte em países pobres, onde os consumidores têm menos chances de usar sua condição como instrumento político. $\mathrm{O}$ atendimento das necessidades desses consumidores deve resultar não só em desempenho superior das empresas, mas deve também contribuir para o desenvolvimento socioeconômico (veja Bloom e Greyser, 1981).

Correspondentemente, apesar do argumento dominan- 
te de que, devido ao advento da globalização, vivemos atualmente em um mundo "sem fronteiras" e sem ideologias políticas (Sheth, 1992), o marketing em países com diferentes níveis de desenvolvimento - como historicamente defendido por autores vinculados ao macromarketing (Bartels e Jenkins, 1977; Dholakia e Nason, 1984) e ao marketing comparado (Boddewyn, 1981) - deve ter perspectivas e elaborar agendas específicas de pesquisa. Este artigo argumenta que a pesquisa no âmbito de estratégia de marketing não deve meramente copiar as agendas dominantes estabelecidas nos Estados Unidos.

\section{Assimetria acadêmica}

$\mathrm{O}$ quadro de assimetria de mercado trazida pela globalização também se observa no contexto da academia. A produção acadêmica em marketing no Brasil é majoritariamente subordinada ao que é produzido nos Estados Unidos (Vieira, 2003). Esse quadro se observa em quase todos os países, e não apenas na área de Marketing. A hegemonia dos Estados Unidos na área de Administração tem crescido no contexto da globalização e provocado reações em muitos países, inclusive nos Estados Unidos (Boyacigiller e Adler, 1991).

Dentre as justificativas para que acadêmicos de marketing no Brasil desafiem esse quadro de assimetria, destacamos duas. Primeiro, porque, conforme reconhecido até mesmo por alguns de seus principais construtores e beneficiários, o sistema de marketing norte-americano tem sido acusado por alguns de "acrescentar vários 'males' à sociedade como um todo" (Kotler e Armstrong, 1999, p. 476). Segundo, porque essa hegemonia acadêmica não se traduz necessariamente em relevância. Autores baseados em alguns países da Europa argumentam que ao longo das últimas décadas a "teoria geral de gerência de marketing não teve nenhum desenvolvimento substancial" (Gummesson, 2001, p. 29) e que a disciplina não "atingiu nem a utopia acadêmica de status científico nem melhorou significativamente as práticas dos gerentes da área" (Brown, 1996, p. 257).

Importantes pesquisadores baseados nos Estados Unidos também vêm fazendo críticas à relevância da área. Esses autores não têm sido ouvidos com a devida atenção porque também enfrentam os efeitos da assimetria acadêmica dentro dos Estados Unidos.

É consenso entre esses autores que a principal causa da baixa relevância do conhecimento dominante em marketing é a dominância do positivismo estatístico na área. O positivismo distancia acadêmicos de praticantes (Day e Montgomery, 1999), e, ao se tornar um obstáculo para o "pluralismo crítico" (Hunt, 1994), amplia o quadro de assimetria acadêmica e impede que "a sociedade, os estu- dantes, a prática de marketing e a academia" (Hunt, 1994, p. 22) sejam igualmente reconhecidos pela área.

Esse quadro explica por que pesquisadores europeus argumentam que o conhecimento acadêmico em OPM produzido nos Estados Unidos, independentemente das diferentes correntes seguidas (Lafferty e Hult, 2001), é irrelevante por ser baseado em manipulações estatísticas de variáveis escolhidas à la carte pelos pesquisadores (Harris, 2002; Henderson, 1998; Piercy, 2002; Wensley, 1995). Esse tipo de conhecimento, além de esvaziar o argumento de que o conceito de OPM é fundamentado na idéia de implementação, mascara as influências do pesquisador e de suas teorias sobre os resultados empíricos (Kuhn, 1970) e reforça os mitos da "observação objetiva da realidade" (Anderson, 1983, p. 20) e da "neutralidade científica" na área (Desmond, 1995).

Outro problema é que a pesquisa dominante em OPM desconsidera questões de poder e de política - dentre outras razões, por marginalizar outras epistemologias acadêmicas - que são centrais para a área de estratégia (Whittington, 2001) e para o âmbito de estratégia de marketing (Morgan e Strong, 1998).

Mais especificamente, a pesquisa em OPM desloca e enfraquece duas importantes agendas de pesquisa que foram propostas nos anos 1980 nos Estados Unidos. A primeira argumentava que o tradicional foco da disciplina na gerência de marketing - centrado na formulação do marketing mix - seria substituído pelo foco na estratégia de marketing - centrado na busca de vantagem de longo prazo (Wind e Robertson, 1983) devido à necessária ascensão do marketing na grande empresa. A segunda argumentava que, por meio do desenvolvimento do âmbito de estratégia de marketing, a área teria papel central para o desenvolvimento de teorias e práticas em estratégia (Day e Wensley, 1983).

A literatura dominante em OPM enfraqueceu essas agendas, e isso influenciou as agendas de pesquisa em outros contextos. Tal fato vem contribuindo tanto para reduzir a relevância da disciplina nesses contextos quanto para enfraquecer as agendas de pesquisa em estratégia de marketing.

\section{Agendas locais de pesquisa e as assimetrias}

Uma das razões da enorme influência da academia dos Estados Unidos no cenário mundial na área de Marketing é o papel cumprido pelo Marketing Science Institute (MSI) e pela American Marketing Association (AMA). A preocupação central dessas instituições não é somente a produção acadêmica, mas principalmente a construção de agendas de pesquisa e a disseminação de conhecimento. O papel dessas instituições se intensificou recentemente 
devido ao advento da globalização, e isso ajuda a explicar, em alguns países da Europa, o crescimento da literatura crítica na área (Burton, 2001) e as críticas contundentes quanto às agendas de pesquisa construídas nos Estados Unidos (veja Wensley, 2000).

Tampouco surpreende que os trabalhos em Marketing publicados no Brasil não desafiem o status quo da área. Desafiar o conhecimento dominante na área é muito difícil, mesmo dentro dos Estados Unidos. Isso exige que o pesquisador lide de forma franca com as seguintes questões: (a) a quem interessa a pesquisa?; (b) para que a pesquisa?; e (c) a pesquisa é boa ou ruim da perspectiva de quem? (Wensley, 1998, p. 83; Dholakia e Nason, 1984, p. 50).

Preocupados há mais tempo com essas questões de relevância e contando com mais recursos do que os pesquisadores de países tidos como menos desenvolvidos, é crescente o número de pesquisadores, em alguns países da Europa, que desafia o status quo da área e promove agendas locais de pesquisa. Dentre os argumentos mobilizados por esses pesquisadores, três merecem destaque: (a) o Marketing não é uma ciência "universal" ou "neutra"; (b) a pesquisa deve contemplar as características sociais, políticas, econômicas e culturais locais; e (c) a relevância da disciplina deve focar principalmente os interesses dos praticantes e da sociedade e não exclusivamente os dos acadêmicos (Brownlie et al., 1999).

A maioria dos pesquisadores nos Estados Unidos tem ignorado as críticas publicadas na Europa e prossegue numa postura extremamente otimista acerca da expansão da economia de mercado e da importância estratégica da disciplina para as grandes empresas no contexto da globalização. A difusão de pesquisa em OPM ao longo dos anos 1990 e a exportação mais recente do conceito para organizações públicas e economias emergentes (Cervera et al., 2001), inclusive para países do Leste Europeu, e de agendas de pesquisa são resultantes dessa postura.

Esse quadro contemporâneo de disputas e de assimetria reproduz a própria história da área nos Estados Unidos. A seguir, desenvolve-se uma análise sócio-histórica da evolução da disciplina nos Estados Unidos para se mostrar como e por que o conceito de OPM enfraqueceu a importância de questões de política e de poder que eram centrais nas agendas de pesquisa em estratégia de marketing.

\section{UMA REVISÃO CRÍTICA DA LITERATURA}

Esta seção é dividida em três partes. Na primeira, desenvolve-se uma breve análise histórica do marketing nos Estados Unidos. Na segunda parte, analisa-se a evolução da disci- plina no contexto da Guerra Fria. Na terceira, apresenta-se uma análise sócio-histórica do conceito de OPM.

\section{Uma análise sócio-histórica do marketing}

O marketing é importante demais nos Estados Unidos para ser desafiado por pesquisadores de países tidos como menos desenvolvidos. Pesquisadores e instituições nesses países enfrentam ao menos três obstáculos: (a) como obter reputação sem reproduzir ou citar a literatura dominante produzida nos Estados Unidos? (Chandy, 2003); (b) como publicar trabalhos nos principais periódicos e congressos acadêmicos? (Whitley, 1984); (c) como obter a colaboração e os recursos de grandes empresas estrangeiras sem privilegiar o conhecimento dominante? (Sharrock, 2000; Zell, 2001).

Por outro lado, cabe destacar que diversos autores importantes, mesmo nos Estados Unidos, estão criticando abertamente a baixa relevância da disciplina e a resistência das empresas em implementar os princípios construídos pela academia (Brownlie et al., 1999; Piercy, 1998; Varadarajan e Jayachandran, 1999; Wensley, 1995). As críticas se concentram na influência do positivismo estatístico na área (Day e Montgomery, 1999; Hunt, 1994) e no desprezo da academia dos Estados Unidos por questões de poder e de implementação (Bonoma, 1985; Dibb e Stern, 2000; Whittington e Whipp, 1992).

Esses dois problemas são historicamente interdependentes. O processo de "cientificação" da área e o imperativo do publish or perish (Wilkie e Moore, 2003) que se estabeleceu a partir do início dos anos 1970 nos Estados Unidos ajudaram a enfraquecer o interesse por questões de implementação e de poder. Tais questões eram tidas como importantes para agendas de pesquisa até o final dos anos 1980 nos Estados Unidos por pesquisadores focados no âmbito de estratégia de marketing (Day e Wensley, 1983; Driver e Foxall, 1986; Walker e Ruekert, 1987). A partir do início dos anos 1990, essas questões foram deslocadas e esquecidas. Para isso, teve central importância a campanha de "propaganda" em favor do conceito de OPM veiculada no Journal of Marketing (Kohli e Jaworski, 1990; Narver e Slater, 1990) e em importantes periódicos de gerência, tais como a Harvard Business Review e a California Management Review (veja Ottensen e Gronhaug, 2002).

Pesquisadores preocupados em constituir agendas de pesquisa no Brasil devem, por conseguinte, reconhecer que o conhecimento acadêmico não é imaculadamente neutro nem mesmo nos Estados Unidos. Vieira (2003), por exemplo, argumenta que os pesquisadores no Brasil deveriam produzir pesquisa local porque o domínio da produção acadêmica dos Estados Unidos vem afastando 
os pesquisadores brasileiros de seu próprio contexto. Essa questão cultural, ou intercultural, não é a única a ser considerada no Brasil por aqueles que buscam a constituição de agendas de pesquisa porque os pesquisadores nos Estados Unidos também são afetados pelo tipo de conhecimento dominante produzido nesse país e pelo quadro correspondente de assimetria acadêmica.

Por conseguinte, a constituição de agendas de pesquisa no Brasil não deve ser guiada tão e somente pela aversão à academia norte-americana ou pelo propósito de construir conhecimento que seja "culturalmente" adequado. A constituição de agendas no Brasil deve contemplar agendas de pesquisa não dominantes nos Estados Unidos (veja, por exemplo, Varadarajan, 1992), e também uma análise mais profunda a respeito de mecanismos e interesses que ajudam a construir o conhecimento dominante em marketing nos Estados Unidos.

A literatura mais recente em Administração tem argumentado com freqüência que os pesquisadores, seus interesses e seus textos são, de alguma forma, influenciados pelo contexto (Alvesson e Sköldberg, 2000; Easterby-Smith et al., 1999). Análises recentes têm mostrado que a hegemonia da academia norte-americana em Administração é explicada, dentre outros fatores, por interesses de colonização e de dominação ideológica (Caldas e Wood, 1997; Locke, 1996; Wensley, 2000). Conseqüentemente, é importante reconhecer por que a academia dos Estados Unidos produz e exporta certo tipo de conhecimento em Marketing.

Um dos mais conhecidos vieses culturais nos Estados Unidos é a sede do novo. No meio acadêmico, "o velho é descartado como obsoleto" (O'Shaughnessy, 1985, p. 2425) e a novidade é confundida com relevância. Para muitos, essa obsessão pelo novo é explicada pela busca de liderança científica. Essa obsessão ajuda a explicar por que os pesquisadores nos Estados Unidos desprezam o contexto, a história, o governo e outras influências em seus textos e pesquisas (Boyacigiller e Adler, 1991; Savitt, 2000).

\section{Disciplina de Marketing no contexto da Guerra Fria}

Logo após a Segunda Guerra Mundial, e no contexto da Guerra Fria, as grandes empresas enfrentavam forte oposição dentro dos Estados Unidos devido ao temor de que monopolizassem os mercados e promovessem abusos contra consumidores, trabalhadores e governos (Dunlop, 1980). Naquela época, as grandes empresas queriam ser vistas como instituições mais sólidas e confiáveis do que o Estado, e ainda capazes de liderar a promoção de desenvolvimento e bem-estar social nos Estados Unidos e, eventualmente, em outros países.
Nesse contexto histórico, foram estabelecidas bases científicas para um novo capitalismo, made in USA, liderado por grandes empresas (Chandler, 1962). Esse capitalismo gerencial (Chandler, 1977) seria governado pela "mão visível" dos gerentes assalariados das grandes empresas, não por membros do governo, de famílias ou da elite financeira. Esses gerentes, apoiados nos princípios do método científico e nos ideais de democracia e meritocracia, passaram a ser descritos na literatura norte-americana como os principais agentes da economia. A grande empresa, que passou a ser descrita como instituição mais eficiente do que o mercado ou que o Estado, e o gerente assalariado eram descritos como os responsáveis pelo extraordinário desempenho econômico dos Estados Unidos após a Segunda Guerra Mundial (Locke, 1996).

Os conceitos de marketing e de orientação para o marketing, apoiados em agendas de pesquisa específicas focadas na ciência do comportamento do consumidor (Tadajewski, 2006), ajudaram a solidificar a idéia de que o mercado era complexo demais para ser manipulado ou controlado por grandes empresas. Esses conceitos e idéias facilitaram a expansão da grande empresa nos Estados Unidos e em outros países, e também a exportação de produtos/serviços e idéias made in USA.

A teoria de sistema mundial, não obstante a forma simplificada com que dominados e dominadores são representados, ajuda a explicar o processo de internacionalização do conhecimento acadêmico de marketing durante a Guerra Fria. Essa teoria divide o mundo entre o centro hegemônico e a periferia. O centro assume responsabilidades de "direção" e transfere suas teorias sociais e convicções ideológicas "para os Estados periféricos, os quais, por sua vez, remodelam suas instituições de acordo com o centro" (Locke, 1996, p. 36).

Imediatamente após a Segunda Guerra Mundial, os Estados Unidos detinham 75\% do PIB do planeta, e nas duas décadas seguintes suas corporações multinacionais dominaram o comércio internacional (Boyacigiller e Adler, 1991). O conceito de marketing, tido como universal nos Estados Unidos e em outros países, ajudou a sedimentar a idéia de que qualquer mercado de consumidores era complexo demais para ser manipulado por grandes empresas, mesmo em economias menos desenvolvidas. Aproveitando esse conceito, as estratégias corporativas das grandes empresas puderam mais facilmente implementar estratégias focadas no bloqueio da concorrência e na dominação dos mercados, tanto no exterior quanto nos Estados Unidos (Knights e Morgan, 1991; Whittington, 2001).

Essa contradição não se transformou em problema político maior porque havia o apoio do governo. Uma das 
principais estratégias do governo dos Estados Unidos na Guerra Fria consistia em construir e exportar representações científicas que ajudassem a impedir que indivíduos, inclusive acadêmicos, fossem atraídos pela representação construída e difundida pelo principal "inimigo" do capitalismo americano: um mundo governado por um Estado que monopoliza a produção de bens e serviços para atender não a necessidades e desejos de indivíduos, mas sim a direitos coletivos. Esse "inimigo" também usava o conhecimento científico para defender sua ideologia. Esse cenário de disputas e interesses ajuda a explicar por que a área de Marketing nos Estados Unidos se sentiu obrigada "a provar a si mesma ser "mais científica do que a ciência' por meio do uso de 'métodos rigorosos"' (Alvesson e Willmott, 1996, p. 120).

Esse quadro influenciou as agendas de pesquisa nos Estados Unidos (veja Tadajewski, 2006) e, subseqüentemente, em outros países. Isso ajuda a explicar por que a pesquisa em comportamento do consumidor seguiu uma trajetória de positivismo extremo e tornou-se a principal "vitrine" da área nos Estados Unidos, e também por que os âmbitos do macromarketing e da política pública de marketing foram discriminados (veja Wilkie e Morre, 2002).

A academia norte-americana de Marketing acabou ajudando a construir uma representação extrema de mundo e de mercado ao longo da Guerra Fria. Esta se baseava em relações justas de troca entre consumidores livres e empresas livres governadas por gerentes assalariados e competentes. Essa representação de mercado e de mundo reproduzia os discursos de mercado livre, livre empresa e consumidor livre (Sassower, 1988) que foram mobilizados nos Estados Unidos para defender e facilitar a exportação de determinado tipo de capitalismo (Gilpin, 1987). Ela suprimia as teorias concorrentes que ressaltavam as "estruturas de dominação e exploração que moldavam e mediam os relacionamentos" de mercado (Alvesson e Willmott, 1996, p. 120).

Essa representação era composta por três princípios fundamentais: (a) os indivíduos satisfazem suas necessidades e seus desejos por meio do consumo e da livre escolha; (b) os gerentes das empresas livres promovem o desenvolvimento socioeconômico por meio do atendimento às necessidades e desejos dos consumidores, e (c) o Estado cria incentivos e algumas poucas regras para não intervir nesse mercado de trocas. Ela não foi muito difícil de se construir, não apenas porque os pesquisadores estavam influenciados pela ideologia da Guerra Fria, mas também por causa da substancial influência econômica e política das grandes corporações e do governo sobre a academia dos Estados Unidos (Roszak, 1968; Philo e Miller, 2001).

Esses princípios extremos desprezaram outros tipos de capitalismo e de mercado, tais como aqueles observados em países como a França ou o Japão (Gilpin, 1987). Isso ajuda a explicar por que o marketing, tal como construído nos Estados Unidos, enfrentou e continua enfrentando tantas dificuldades para ser assimilado na Europa.

No contexto da Guerra Fria, os conceitos de marketing e de orientação para marketing tiveram importância estratégica tanto para as grandes corporações quanto para o governo dos Estados Unidos. Esses conceitos enfraqueceram a principal "teoria rival" da época, que afirmava que uma economia política sem um mercado livre e monopolizada (ou mesmo regulada, como em diversos países da Europa e no Japão) pelo Estado pudesse ser a mais benéfica para cidadãos e trabalhadores.

No final das contas, embora fossem apresentados como relevantes para consumidores e eventualmente para praticantes, os conceitos de marketing e de orientação para o marketing eram de fato relevantes especialmente para o governo dos Estados Unidos e para a maioria das grandes empresas. O papel ideológico desses conceitos ajuda a explicar por que a constituição de agendas de pesquisa na área de marketing tornou-se um tabu em países tidos como menos desenvolvidos.

Apoiados por acadêmicos sediados em diversos países, esses conceitos ajudaram a reduzir resistências de governos, cidadãos e acadêmicos locais à entrada das grandes corporações e de seus produtos, interesses e outras bagagens ideológicas. Isso ajuda a explicar por que na Europa o marketing ainda é tido mais como ideologia do que como conceito (Brownlie e Saren, 1992). E porque autores mais críticos classificam o marketing como a disciplina da Administração "para a qual a teoria crítica (e tradições intelectuais relacionadas) mais pode contribuir e também aquela em que é mais fraca a influência da análise crítica" (Alvesson e Willmott, 1996, p. 128).

Cabe destacar, entretanto, que os consumidores e praticantes de marketing nos Estados Unidos (Barksdale e Darden, 1972) manifestaram descrença quando os acadêmicos e as grandes corporações anunciaram que o princípio de que "você pode ter o carro da cor que quiser desde que seja preta" - e de que a correspondente orientação para a produção e orientação para vendas (Kotler e Armstrong, 1999; Fullerton, 1988) - estavam sendo definitivamente substituídos pela orientação para o marketing devido aos benefícios advindos dessa nova orientação para as grandes empresas e, conseqüentemente, para a sociedade. 
Essas manifestações não foram valorizadas pelos acadêmicos não somente por causa dos interesses políticos e econômicos que predominavam na época, mas principalmente porque eles se sentiam, profissional e ideologicamente, obrigados a desafiar preconceitos históricos contra grandes empresas, marketing e marketers (Steiner, 1976). Na economia capitalista mais poderosa do mundo, esses acadêmicos de marketing acabaram se transformando em autoridades intelectuais (Hughes, 1980). Além disso, a afluência econômica da classe média nos Estados Unidos, o elevado desempenho econômico das grandes empresas - explicado em grande parte não exatamente pela aplicação dos princípios científicos fornecidos pela academia de administração, mas principalmente pelos benefícios advindos do Plano Marshall (Gilpin, 2004) - e a ascensão socioeconômica da classe gerencial atenuaram naquela época as manifestações de descrença e oposição, e também ajudaram a moldar a percepção dos acadêmicos de marketing.

O fortalecimento do consumerismo como movimento organizado contra os abusos das grandes empresas nos Estados Unidos também não foi valorizado porque a maioria dos pesquisadores estava comprometida com agendas de pesquisa focadas no ideal de satisfação do consumidor e descomprometida com o âmbito de políticas públicas de marketing (Hollander et al., 1999).

Cabe destacar, entretanto, que tanto o movimento do consumerismo quanto a evolução da disciplina nos Estados Unidos (Bloom e Greyser, 1981) foram diretamente influenciadas pelo governo de John Kennedy, no início da década de 1960. A legislação correspondente, que tinha como principal objetivo coibir os abusos das grandes empresas sobre os consumidores (veja Churchill e Peter, 2000), foi de central importância para a constituição de departamentos de Marketing dentro das grandes empresas e para o fortalecimento acadêmico da área. A resistência da alta hierarquia aos princípios "altruístas" de marketing ao longo dos anos 1970 ajuda a explicar por que o âmbito da estratégia de marketing foi apontado nos anos 1980 como de central importância para a implementação de tais princípios.

A influência do governo no mercado e a importância política do domínio da estratégia de marketing nas grandes empresas foram esquecidas a partir de meados dos anos 1980, quando foi iniciado um extenso e profundo processo de reforma do Estado nos Estados Unidos. Este resultou em um conjunto de políticas de desregulamentação de mercados e o conseqüente fortalecimento das grandes empresas (Tiemstra, 1992).
O anúncio do fim da Guerra Fria no início dos anos 1990 não apagou na academia os mecanismos, estruturas, interesses e discursos correspondentes (Gray, 2002). Segundo alguns autores, a globalização e as "forças de mercado" reduziram ainda mais a autonomia da academia norte-americana (Frank, 2002; Klein, 2000; Philo e Miller, 2001; Zell, 2001). Isso ajuda a explicar o poder alcançado pelo conceito de OPM e pelo discurso subjacente de "mercado livre" em curto período, a partir do início dos anos 1990.

\section{Uma análise do conceito de OPM no contexto da globalização}

Antes de analisarmos a constituição do conceito de OPM, cabe ressaltar que a exportação para a Europa de conhecimento de marketing construído nos Estados Unidos tem sido problemática. Tanto os consumidores como os acadêmicos locais, influenciados também pela Guerra Fria e por um contexto político-econômico em que a grande empresa tem menos poder político do que nos Estados Unidos, questionaram e continuam questionando a relevância e a legitimidade da disciplina (Arndt, 1985; Brownlie e Saren, 1992; Dickinson et al., 1988).

Dois pontos de interesse para esta seção são o não-alinhamento de alguns acadêmicos europeus ao conceito de OPM e a insistência em problematizar questões de implementação e de relevância (veja Brownlie e Saren, 1997; Henderson, 1998; Piercy, 2002; Wensley, 1995; Whittington e Whipp, 1992).

O imenso volume de textos e discursos sobre a globalização produzido e publicado nos Estados Unidos estabeleceu, a partir do início dos anos 1990, o entendimento de que, sem os temores e as tensões causadas pela Guerra Fria, as grandes empresas estariam livres das restrições impostas por Estados e governos nacionais. As grandes corporações poderiam a partir de então atuar de forma mais efetiva em praticamente todos os países ou mercados - os participantes do chamado mercado global - e liderar o processo de desenvolvimento pleno do capitalismo em detrimento de outros tipos nacionais de capitalismo (veja Radice, 2000).

Países e culturas foram transformados em mercados e consumidores, e foram retratados como indivíduos que poderiam aproveitar os privilégios desse novo "mercado sem fronteiras". Nos Estados Unidos, essa representação de mundo global foi acompanhada de um significado particular de autoridade e hegemonia porque essa nova realidade mostrava que a guerra entre mercado e Estado teria sido vencida pelo primeiro.

De fato, o ocaso da Guerra Fria e o advento da glo- 
balização foram marcados nos Estados Unidos por uma atmosfera de euforia e vitória parecida com aquela experimentada após a Segunda Guerra Mundial. Essa atmosfera e os discursos correspondentes construídos no início dos anos 1990 ajudam a explicar por que acadêmicos de marketing perderam o interesse pelas agendas de pesquisa em estratégia de marketing nos anos 1980 .

Mais especificamente, os discursos de que as grandes corporações estavam sob grande risco por terem que competir em mercados desconhecidos e com empresas de outras origens nacionais levaram à construção de representações extremas de competição. A idéia de que a estratégia das empresas no mercado "global" deveria ser o mais coesa possível devido ao regime de hipercompetição facilitou o abandono de questões políticas entre os níveis da estratégia de marketing e da estratégia corporativa (veja, por exemplo, Menon et al., 1999).

Pesquisa em OPM confirma a idéia de que nessa nova realidade o departamento de Marketing não faz mais sentido. Porém, os pesquisadores ignoram a proposição de que o departamento não faz mais sentido porque o marketing se tornou irrelevante (Brown, 1996; Shaw, 1999) ou foi colonizado pela alta hierarquia (Day, 1992; Hooley et al., 2005). Pesquisa focada em OPM enfraquece essas questões políticas e de poder, de central importância para o âmbito da estratégia de marketing, por meio da imposição de dois pressupostos problemáticos: (a) todos são responsáveis pelo marketing na grande empresa, e (b) a alta hierarquia garante a necessária coesão interna e a implementação dos princípios correspondentes (veja Achrol e Kotler, 2000; Jaworski e Kohli, 1993; Narver e Slater, 1990; Webster, 1992).

Além de ignorar as disputas históricas entre o departamento de Marketing e a alta hierarquia, que foram ressaltadas pelo âmbito da estratégia de marketing (Boxer e Wensley, 1986; Day e Wensley, 1983; Driver e Foxall, 1986), o conceito de OPM reforça e amplia as ideologias de mercado livre, empresa livre e consumidores livres construídas na Guerra Fria.

Tendo em vista as assimetrias contemporâneas que vêm sendo ampliadas e evidenciadas pelas grandes corporações devido à proliferação de estratégias focadas na dominação de mercados, inclusive de governos, e no bloqueio da concorrência, e devido também à crescente influência dessas corporações nas agendas de pesquisa na área de Marketing, argumenta-se neste artigo que uma agenda brasileira de pesquisa em estratégia de marketing deve ter como um dos focos principais a problematização do crescente poder político e econômico das grandes corporações no contexto da globalização, em especial em economias tidas como menos desenvolvidas.

\section{CONSIDERAÇÕES FINAIS}

Este artigo mostrou que conhecimento dominante de marketing não pode ser tido como neutro, nem mesmo nos Estados Unidos. Por meio de uma abordagem histórica de análise, o autor mostrou que, assim como ocorrera com os conceitos de marketing e orientação para o marketing no contexto da Guerra Fria, o conceito de OPM reproduz, no contexto da globalização, interesses que devem ser desafiados, principalmente em países tidos como menos desenvolvidos.

O conceito de OPM ajudou a enfraquecer o âmbito da estratégia de marketing e também o interesse de pesquisadores por questões de poder e de implementação, primeiramente nos Estados Unidos e em seguida em diversos países. Este artigo mostrou que a área de Marketing é importante demais em países mais desenvolvidos, tanto para as grandes empresas quanto para o Estado e para a sociedade. Todavia, isso não pode justificar a omissão de se elaborarem agendas de pesquisa em países tidos como menos desenvolvidos. $\mathrm{O}$ artigo mostrou que a constituição de agendas de pesquisa no Brasil não deve necessariamente se basear na aversão à academia norte-americana nem se restringir ao mero esforço de adaptar às características locais o conhecimento dominante produzido e publicado nos Estados Unidos.

O conceito de OPM é um obstáculo central para a constituição de agendas de pesquisa em estratégia de marketing. No contexto da globalização, esse conceito reproduz o discurso de mercado livre e legitima de forma particular a transferência de poder do departamento de Marketing para a alta hierarquia. Essa questão é de central importância não somente para corporações globais e para seus praticantes, mas também para a sociedade e para o Estado, especialmente em países tidos como menos desenvolvidos.

Tendo em vista o argumento de que algumas estratégias de marketing de grandes empresas - as quais não seguem os princípios fundamentais do marketing - costumam causar sérios problemas em países tidos como menos desenvolvidos, a agenda de pesquisa delineada neste artigo pode ajudar a produzir conhecimento relevante não somente para consumidores e praticantes de marketing, mas também para governos e sociedades locais. Pesquisadores poderiam, por exemplo, tentar compreender como e por que os praticantes de marketing, a despeito do discurso 
de OPM, conseguem evitar, total ou parcialmente, a colonização do domínio da estratégia de marketing pela alta hierarquia das grandes empresas. Sob uma perspectiva que privilegia tanto questões de poder quanto de política, essas investigações deveriam também avaliar o impacto desse tipo de resistência sobre o "desempenho" segundo as perspectivas da empresa, do consumidor, da sociedade e do governo.

Ao promover a investigação de processos de implementação por meio de abordagens epistemológicas que desafiam o positivismo estatístico, essas pesquisas podem ajudar a evitar a cientificação excessiva da área que se verificou nos Estados Unidos e também a aproximar os pesquisadores da área ao âmbito da política pública e do macromarketing.

Algumas sugestões, apresentadas de forma resumida a seguir devido às limitações de espaço, podem guiar a constituição dessa agenda brasileira de pesquisa em estratégia de marketing:

a) promover pesquisas focadas na análise sócio-histórica da área para evitar tanto a adesão total quanto a aversão total ao conhecimento dominante produzido e publicado nos Estados Unidos;

b) promover a aproximação de pesquisadores e instituições locais a acadêmicos e instituições que desenvolvam agendas de pesquisa (na Europa e nos Estados Unidos, por exemplo) que desafiam o conhecimento dominante em marketing;

c) promover investigações focadas em identificar como e por que as estratégias de marketing conduzidas por departamentos de Marketing de grandes empresas estrangeiras orientadas para o mercado conseguem (ou não) desafiar o âmbito da estratégia corporativa para implementar princípios fundamentais de marketing no Brasil. Que as empresas não se limitem a satisfazer os consumidores, mas também que não abusem deles. E que o atendimento das necessidades desses consumidores resulte em desempenho superior para as empresas e em desenvolvimento socioeconômico;

d) promover orientações de pesquisa que permitam afastar os pesquisadores dos interesses das cúpulas empresariais, aproximando-os de outros pesquisadores, praticantes e consumidores;

e) promover pesquisas que reconheçam a importância do Estado e do âmbito das políticas públicas na esfera da estratégia de marketing no Brasil;

f) promover pesquisas focadas em implementação da estratégia de marketing e do conceito de OPM por meio de diferentes tipos de pesquisa qualitativa.

\section{AGRADECIMENTOS}

O autor agradece aos avaliadores deste artigo pelos comentários, críticas e sugestões feitas. Mais especificamente, agradece a um dos avaliadores pela sugestão de que o título deste trabalho deveria se referir a uma agenda brasileira de pesquisa, em vez da denominação original de "agenda de pesquisa no Brasil". Finalmente, o autor agradece ao CNPq pelo apoio concedido ao projeto que originou este artigo. Todas as suas eventuais falhas são de responsabilidade do autor.

\section{REFERÊNCIAS}

ALVESSON, M.; SKÖLDBERG, K. Reflexive Methodology. London: Sage, 2000

ALVESSON, M.; WILLMOTT, H. Making Sense of Management. London: Sage, 1996.

ANDERSON, P. Marketing, scientific progress, and scientific method. Journal of Marketing, v. 47, n. 4, p. 18-31, Fall 1983.

ARNDT, J. On making marketing science more scientific: role of orientations, paradigms, metaphors, and puzzle solving. Journal of Marketing, v. 49, n. 3, p. 11-23, Summer 1985.

BARKSDALE, H.; DARDEN, W. Consumer attitudes towards marketing and consumerism. Journal of Marketing, v. 36, p. 28-35, 1972.

BARTELS, R.; JENKINS, R. Macromarketing. Journal of Marketing, v. 41, n. 4, p. 17-20, 1977

BLOOM, P.; GREYSER, S. The maturing of consumerism. Harvard Business Review, v. 59, n. 6, p. 130-139, 1981

BODDEWYN, J. Comparative marketing: the first twenty-five years. Journal of International Business Studies, v. 12, n. 1, p. 61-79, 1981

BONOMA, T. Case research in marketing: opportunities, problems and a process. Journal of Marketing, v. 22, n. 2, p. 199-208, 1985.

BOUGIE, R.; PIETERS, R.; ZEELENBERG, M. Angry customers don't come back, they get back: the experience and behavioral implications of anger and dissatisfaction in services. Journal of the Academy of Marketing Science, v. 31, n. 4, p. 377-393, 2003.

BOXER, P.; WENSLEY, R. The need for middle-out development of marketing strategy. Journal of Management Studies, v. 23, n. 2, p. 189-204, 1986.

BOYACIGILLER, N.; ADLER, N. The parochial dinosaur: organizational science in a global context. Academy of Management Review, v. 16, n. 2, p. 262-290, 1991.

BROWN, S. Art or Science? Fifty years of marketing debate. Journal of Marketing Management, v. 2, n. 1, p. 243-267, 1996. 


\section{FÓRUM • EM BUSCA DE UMA AGENDA BRASILEIRA DE PESQUISA EM ESTRATÉGIA DE MARKETING}

BROWNLIE, D.; SAREN, M. Beyond the one-dimensional marketing manager: the discourse of theory, practice and relevance. International Journal of Research in Marketing, v. 14, n. 2, p. 147-161, 1997.

BROWNLIE, D.; SAREN, M. The four P's of the marketing concept: prescriptive, polemical, permanent and problematical. European Journal of Marketing, v. 26, n. 4, p. 34-48, 1992

BROWNLIE, D.; SAREN, M.; WHITTINGTON, R.; WENSLEY, R. (Eds.). Rethinking Marketing. London: Sage, 1999.

BURTON, D. Critical marketing theory: the blueprint? European Journal of Marketing, v. 35, n. 5/6, p. 722-735, 2001.

CALDAS, M.; WOOD JR., T. For the English to see: the importation of managerial technology in late 20th century. Organization, v. 4, n. 4, p. 517-534, 1997.

CERVERA, A.; MOLLÁ, A.; SANCHEZ, M. Antecedents and consequences of market orientation in public organizations. European Journal of Marketing, v. 35, n. 11/12, p. 1259-1286, 2001.

CHANDLER, A. Strategy and Structure. Cambridge, MA: MIT Press, 1962.

CHANDLER, A. The Visible Hand. Cambridge, MA: Harvard University, 1977

CHANDY, R. Research as innovation: rewards, perils, and guideposts for research and reviews in marketing. Journal of the Academy of Marketing Science, v. 31, n. 3, p. 351-355, 2003.

CHAUVEL, M. Consumidores insatisfeitos - Uma oportunidade para as empresas. Rio de Janeiro: Mauad, 2000.

CHURCHILL JR, G.; PETER, J. Marketing - Criando valor para os clientes. São Paulo: Saraiva, 2000.

CRAVENS, D. Implementation strategies in the market-driven strategy era. Journal of the Academy of Marketing Science, v. 26, n. 3, p. 237-241, 1998.

DAY, G. Marketing's contribution to the strategy dialogue. Journal of the Academy of Marketing Science, v. 20, n. 4, p. 323-329, 1992.

DAY, G.; MONTGOMERY, D. Charting new directions for marketing. Journal of Marketing, v. 63, n. 4, p. 3-13, 1999.

DAY, G.; WENSLEY, R. Marketing theory with a strategic orientation. Journal of Marketing, v. 47, n. 4, p. 79-89, 1983.

DESMOND, J. Reclaiming the subject: deco modifying marketing knowledge? Journal of Marketing Management, v. 11, n. 7, p. 721-746, 1995.

DHOLAKIA, N.; NASON, R. Research issues in macro-marketing: a blueprint for progress. European Journal of Marketing, v. 18, n. 1, p. 41-55, 1984
DIBB, S.; STERN, P. Further thoughts on the marketing trifid: the case of marketing orientation. Journal of Marketing Education, v. 22, n. 3, p. $214-224,2000$

DICKINSON, R.; HERBST, A.; O'SHAUGHNESSY, J. The marketing concept and customer orientation. European Journal of Marketing, v. 20, n. 10, p. 18-23, 1988.

DOBNI, C.; LUFFMAN, G. Implementing marketing strategy through market orientation. Journal of Marketing Management, v. 16, n. 8, p. 895916,2000

DOUGLAS, S.; CRAIG, S. Global marketing myopia. Journal of Marketing Management, v. 2, n. 4, p. 155-169, 1986.

DRIVER, J.; FOXALL, G. Marketing strategy in corporate context. Journal of General Management, v. 11, n. 3, p. 5-14, 1986.

DUNLOP, J. (Ed.). Business and Public Policy. Boston, MA: Harvard University, 1980

EASTERBY-SMITH, M.; THORPE, R.; LOWE, A. Pesquisa gerencial em Administração. São Paulo: Pioneira, 1999.

FRANK, T. One Market Under God. London: Vintage, 2002.

FULLERTON, R. How modern is modern marketing? Journal of Marketing, v. 52 , n. 1 , p. $108-25,1988$

GENTRY, J.; JUN, S.; TANSUHAJ, P. Consumer acculturation processes and cultural Conflict. Journal of Business Research, v. 32, n. 3, p. 129139, 1995

GILPIN, R. O desafio do capitalismo global. Rio de Janeiro: Record, 2004.

GILPIN, R. The Political Economy of International Relations. Princeton, NJ Princeton University Press, 1987.

GRAY, H. Cold war universities: tools of power or oases of freedom? Foreign Affairs, v. 76, n. 2, p. 147-151, 2002.

GREENLEY, G. An understanding of marketing strategy. European Journal of Marketing, v. 18, n. 6/7, p. 90-103, 1989

GUMMESSON, E. Are current research approaches in marketing leading us astray? Marketing Theory, v. 1, n. 3, p. 27-48, 2001.

HARRIS, L. Developing market orientation: an exploration of differences in management approaches. Journal of Marketing Management, v. 18, n. $7 / 8$, p. 603-632, 2002

HENDERSON, S. No such thing as marketing orientation - a call for no more papers. Management Decision, v. 36, n. 4, p. 45-59, 1998.

HIRST, P.; THOMPSON, G. Globalização em questão. Rio de Janeiro: Vozes, 2002

HOLLANDER, S.; KEEP, W.; DICKINSON, R. Marketing public policy and the evolving role of marketing academics: a historical perspective. Journal of Public Policy \& Marketing, v. 18, n. 2, p. 265-269, 1999. 
HOOLEY, G.; FAHY, J.; GREENELY, G.; BERACS, J.; FONFARA, K.; SNOJ, B. Market orientation in the service sector of the transition economies of Central Europe. European Journal of Marketing, v. 37, n. 1/2, p. 86-106, 2003.

HOOLEY, G.; SAUNDERS, J.; PIERCY, N. Estratégia de marketing e posicionamento competitivo. São Paulo: Pearson, 2005.

HUGHES, J. The Philosophy of Social Research. Longman: London, 1980.

HUNT, S. On rethinking marketing: our discipline, our practice, our methods. European Journal of Marketing, v. 28, n. 3, p. 13-25, 1994.

HUNT, S.; LAMBE, J. Marketing's contribution to business strategy: market orientation, relationship marketing and resource advantage theory. International Journal of Management Reviews, v. 2, n. 1, p. 17-43, 2000.

JAWORSKI, B.; KOHLI, A. Market orientation: antecedents and consequences. Journal of Marketing, v. 57, n. 3, p. 53-70, 1993.

KERIN, R. In pursuit of an ideal: the editorial and literary history of the Journal of Marketing. Journal of Marketing, v. 60, n. 1, p. 1-13, 1996.

KLEIN, N. No Logo - Taking Aim at the Brand Bullies. London: Vintage, 2000.

KNIGHTS, D.; MORGAN, G. Corporate strategy, organizations, and subjectivity: a critique. Organisation Studies, v. 12, n. 2, p. 251-273, 1991.

KOHLI, A.; JAWORSKI, B. Market orientation: the construct, research propositions and managerial implications. Journal of Marketing, v. 54, n. 1, p. 1-18, 1990.

KORTEN, D. When Corporations Rule The World. San Francisco, CA: Berrett-Koeheler, 2001.

KOTLER, P.; ARMSTRONG, G. Princípios de marketing. Rio de Janeiro: LTC, 1999.

KUHN, T. The Structure of Scientific Revolutions. Chicago: Chicago University Press, 1970.

LAFFERTY, B.; HULT, G. A synthesis of contemporary market orientation perspectives. European Journal of Marketing, v. 35, n. 1/2, p. 92-109, 2001.

LOCKE, R. The Collapse of the American Management Mystique. New York: Oxford University, 1996.

MENON, A.; BHARADWAJ, S.; ADIDAM, P; EDISON, S. Antecedents and consequences of marketing strategy making: a model and a test. Journal of Marketing, v. 63, n. 3, p. 18-40, 1999.

MOORMAN, C.; RUST, R. The role of marketing. Journal of Marketing, v. 63, n. 2, p. 180-197, 1999.
MORGAN, N.; STRONG, C. Market orientation and dimensions of strategic orientation. European Journal of Marketing, v. 32, n. 11/12, p. 10511073, 1998.

NARVER, J.; SLATER, S. The effects of a market orientation on business profitability. Journal of Marketing, v. 54, n. 4, p. 20-35, 1990.

O'SHAUGHNESSY, N. Strategy and US cultural bias. European Journal of Marketing, v. 19, n. 4, p. 23-32, 1985.

PHILO, G.; MILLER, D. Market Killing - What the Free Market Does and what Social Scientists Can Do About It. Essex: Pearson Education, 2001.

PIERCY, N. Consumer satisfaction and the internal marketing: marketing our customers to our employees. Journal of Marketing Practice: Applied Marketing Science, v. 1, n. 4, p. 22-44, 1995.

PIERCY, N. Marketing implementation: the implications of marketing paradigm weakness for the strategy execution process. Journal of the Academy of Marketing Science, v. 26, n. 3, p. 222-236, 1998.

PIERCY, N. Research in marketing: teasing with trivia or risking relevance? European Journal of Marketing, v. 36, n. 3, p. 350-363, 2002.

RADICE, H. Globalization and national capitalisms: theorizing convergence and differentiation. Review of International Political Economy, v. 7, n. 4, p. 719-742, 2000.

ROSZAK, T. (Ed.). The Dissenting Academy. New York: Random House, 1968.

SASSOWER, R. Ideology masked as science: shielding economics from criticism. Journal of Economic Issues, v. 22, n. 1, p. 167-179, 1988.

SAVITT, R. Fernand Braudel on historiography and its implications for marketing history. Journal of Macromarketing, v. 20, n. 1, p. 89-93, 2000.

SETHI, S.; POST, J. Public consequences of private action: the marketing of infant formula in less developed countries. California Management Review, v. 21, n. 4 , p. $35-48,1979$.

SHARROCK, G. Why Students are not (just) customers. Journal of Higher Education Policy and Management, v. 22, n. 2, p. 149-164, 2000.

SHAW, R. Improving Marketing Effectiveness: The Methods that Work Best. London: The Economist Books, 1999.

SHETH, J. Emerging marketing strategies in a changing macroeconomic environment: a commentary. International Marketing Review, v. 9, n. 1, p. 57-63, 1992.

SHRIVASTAVA, P. Is strategic management ideological? Journal of Management, v. 12, n. 3, p. 363-377, 1986.

SOUZA, A. Uma reflexão sobre as influências negativas do marketing e do consumo. Gestão.Org, v. 1, n. 1, p. 73-85, 2003.

STEINER, R. The prejudice against marketing. Journal of Marketing, v. 40, n. 3, p. 2-9, 1976. 
TADAJEWSKI, M. The ordering of marketing theory: the influence of McCarthyism and the Cold War. Marketing Theory, v. 6, n. 2, p. 163199, 2006

TIEMSTRA, J. Theories of regulation and the history of consumerism. International Journal of Social Economics, v. 16, n. 9, p. 3-27, 1992.

VARADARAJAN, P. Marketing's contribution to strategy: the view from a different looking glass. Journal of the Academy of Marketing Science, v. 20, n. 4, p. 335-343, 1992.

VARADARANJAN, P.; JAYACHANDRAN, S. Marketing strategy: an assessment of the state of the field. Journal of the Academy of Marketing Science, v. 27, n. 2, p. 120-143, 1999.

VIEIRA, F. Narciso sem espelho: a publicação brasileira de marketing. RAE - Revista de Administração de Empresas, v. 43, n. 1, p. 81-90, 2003.

WALKER, O.; RUEKERT, R. Marketing's role in the implementation of business strategies: a critical review and conceptual framework. Journal of Marketing, v. 51, n. 3, p. 15-33, 1987.

WEBSTER, F. The changing role of marketing in the corporation. Journal of Marketing, v. 56, n. 2, p. 1-17, 1992.
WENSLEY, R. Falling in love with segmentation. In: BROWN, S.; DOHERTY, A.; CLARKE, B. (Eds). Romancing the Market. London: Routledge, 1998.

WENSLEY, R. A critical review of research in marketing. British Journal of Management, v. 6, Special Issue, p. 36-82, 1995.

WENSLEY, R. The MSI priorities: a critical view on researching firm performance, customer experience and marketing. Journal of Marketing Management, v. 16, n. 2, p. 11-27, 2000.

WhitTingtON, R. O que é estratégia. São Paulo: Pioneira, 2001.

WHITTINGTON, R.; WHIPP, R., Professional ideology and marketing implementation. European Journal of Marketing, v. 26, n. 1, p. 52-63, 1992

WILKIE, W. L.; MOORE, E. S. Scholarly research in marketing: exploring the "4 Eras" of thought development. Journal of Public Policy \& Marketing, v. 22, n.2. p. 116-146, 2003

WIND, Y.; ROBERTSON, T. Marketing strategy: new directions for theory and research. Journal of Marketing, v. 47, n. 2, p. 12-25, 1983.

ZELL, D. The market-driven business school: has the pendulum swung too far? Journal of Management Inquiry, v. 10, n. 4, p. 324-338, 2001.

Artigo recebido em 15.04.2005. Aprovado em 11.07.2006.

\section{Alexandre Faria}

Professor Adjunto da FGV-EBAPE. PhD em Administração pela University of Warwick. Interesses de pesquisa nas áreas de estratégia, estratégia de marketing, marketing, estudos críticos em gestão.

E-mail: afaria@fgv.br

Endereço: Praia de Botafogo, 190, sala 535, Botafogo, Rio de Janeiro - RJ, 22250-900. 